\title{
BREVE EXPOSICIÓN SOBRE LA NATURALEZA DE LO DADO Y LOS VALORES EN LA FILOSOFÍA DE DIETRICH VON HILDEBRAND*
}

"La ética fenomenológica de los valores ve en el valor un algo pluriforme por su contenido, pero objetivo y separado del ser, que reviste carácter apriorístico, confiere al apetito plenitud de sentido y no coincide en modo alguno con la obligación o deber sino que da fundamento al deber"[1]. Según esta definición parcial de la ética fenomenológica de los valores, a mi modo de ver, Hildebrand acoge y rompe a la vez con la ética fenomenológica de los valores, pues, por un lado apuesta por el método fenomenológico para una ética de los valores, pero, por otro lado, hace unos esfuerzos tremendos por no desgajarse nunca del ser. Hildebrand lo dice así: “(...) todo valor es en sí mismo objetivamente un ser (...) Es absurdo pensar que al ser se le añade algo que en sí mismo no es también un ser" [2]. Lo que no se puede identificar es el modo de ser del valor y el modo de ser que tiene el ser al poseer el valor. Tampoco se puede identificar el ser de un valor y el ser de un ser que posee un valor. Ambos son. La diferencia estriba en que el valor es en el ser, se da en él, y el ser es per se. Por eso para Hildebrand el valor y el ser no poseen el mismo contenido al igual que el bien y el ser no son conceptos idénticos sino convertibles. Por eso dirá: “Nosotros hemos visto que los valores no son categorías de motivación sino propiedades del ser, constituyen una realidad absoluta, independientemente de cualquier relación con el hombre. Posee un estatuto objetivo"[3].

La fenomenología de Hildebrand no es una mera descripción de los fenómenos o de todo lo experimentado por el sujeto. Al ser su punto de partida "lo dado inmediatamente", esto es, la voz del ser[4], de lo que se

\footnotetext{
* Artículo publicado en la Rrevista Mayéutica, , ISSN 0210-2900, Navarra, Vol. 35, № 80, 2009 , págs. 403409.
} 
trata es de explicar esa naturaleza de lo dado. Es, pues, dar razón de la esencia dada al sujeto, es mirar con detenimiento la esencia de las cosas, siguiendo el famoso lema fenomenológico de ¡volver a las cosas mismas! Es, al fin y al cabo, filosofar y no hacer conjeturas. Para ello, Hildebrand pone una serie de condiciones para llegar a lo dado inmediatamente. La primera es que hay que eliminar el contenido de la experiencia ingenua, esto es, hay que salir del estado de opinión, de la doxa, a través de la filosofía. Esta catarsis de la doxa será la principal tarea del filósofo. La segunda condición "consiste en eliminar las limitaciones y reducciones accidentales que vienen impuestas por nuestro acceso pragmático al ser" [5]. Esto enlaza con el perfil intelectual que traza su esposa Alice cuando dice: "Es difícil clasificar a Hildebrand en una escuela filosófica específica, porque su punto de partida no son las obras de otros filósofos; su gran maestro es primariamente el propio ser. Su labor creativa se ha de explicar principalmente a través de su actitud básica de receptibilidad a lo que él mismo llama la voz del ser. Por eso, poner su nombre en la lista de los fenomenologistas induce a error porque el significado de la fenomenología en su pensamiento difiere radicalmente del significado dado al término por Husserl y Heidegger. El interés filosófico de Hildebrand está exclusivamente encauzado en dirección a la verdad: por muy revolucionarias que puedan haber sido algunas de sus contribuciones al pensamiento filosófico, nunca ha perseguido la novedad filosófica. Él mismo ha dicho: "nunca he intentado decir algo nuevo, exclusivamente intento decir algo verdadero"[6]. Probablemente esto lo aprendió de su quinta hermana Bértele (Quintilla, como le llamaban en su familia), que "había recibido el raro don de permitir que las cosas hablasen por sí mismas y no se dejaba influenciar por lo que los demás decían de ellas"[7].

Una vez superadas las dos condiciones que nos propone Hildebrand, debemos hacer hincapié en la naturaleza de lo dado. ¿A qué se refiere nuestro autor cuando nos habla de lo dado inmediatamente? Siguiendo los prolegómenos de su Ética, lo dado es “(...) una entidad necesaria e inteligible, el único objeto verdadero de la filosofía, como son, por ejemplo, el ser, la verdad, el conocimiento, el espacio, el tiempo, el hombre, la justicia, la injusticia, los números, el amor, la voluntad y muchos otros. Es el objeto que posee una esencia necesaria, profundamente inteligible, que se impone por sí mismo a nuestro espíritu, que se revela y se muestra como válido 
cuando se le mira en una intuición intelectual"[8]. Esa intuición intelectual (Einsicht) es una intuición originaria, una experiencia primera, una forma de contacto cognoscitivo en el cual una esencia se revela de modo inmediato al intelecto debido a su propia inteligibilidad e independientemente de su percepción sensible. Con esto Hildebrand quiere hacer justicia con el dato, con lo dado[9]. Estudiar lo dado es poner empeño en la esencia de lo que primeramente conocemos, y esta va a ser la prioridad de la filosofía de Hildebrand. Después de conocer las esencias, que es lo genuinamente filosófico y lo que le fascinó en Gotinga, se estudiará lo dado en relación con otros datos de nuestro conocimiento. Con todo, no se pretende construir un sistema[10], sino la realización de una investigación sistemática. Este método tan riguroso y ordenado en nada tiene que ver con una producción teórica al modo de Descartes, Spinoza o Kant. No tiene cabida construir una realidad a partir de lo dado, sino que con lo dado vamos conociendo la realidad. Esto de ningún modo es afín a cualquier tipo de idealismo. Para ello necesitamos de la contemplación, esto es, de una mirada limpia y fiel de lo que el ser nos envía. Por tanto, a diferencia de las ciencias que se detienen más en la observación, la filosofía debe detenerse más en la contemplación. Y contemplar es mirar lo realmente importante, las esencias de lo dado. La actitud del filósofo será entonces contemplativa, una actitud que, además de dar por supuesto la natural (actitud natural), implica un compromiso con lo contemplado[11]. La coherencia de la vida contemplativa lleva a la vida comprometida, y en este marco de compromiso (con la realidad misma del ser) nace la ética. Hildebrand lo dice así: “La investigación ética se funda en nuestras capacidades naturales de conocimiento (...). Nuestra intención es captar la esencia de esta moralidad y de todos los factores que determinan su presencia, en la medida en que son accesibles a nosotros por la luz natural de nuestra razón" [12].

Parece obvio que un estudio de lo dado en el campo de la ética implique un estudio de lo dado en el campo de la voluntad y de nuestra afectividad. Lo dado debe tener una respuesta en el sujeto no sólo en el ámbito del conocimiento, sino también en el ámbito de nuestra voluntad, pero no todo lo dado mueve necesariamente nuestra afectividad, no todo lo dado nos afecta en nuestro vivir, en nuestra conducta. Por ello, la ética de Hildebrand se centrará en el dato que tenga la capacidad de obtener una respuesta afectiva, y ese dato que tenga tal capacidad deberá tener el 
carácter de importancia (Bedeutsamkeit). "Llamaremos importancia al carácter que permite que un objeto llegue a ser fuente de una respuesta afectiva o motive nuestra voluntad"[13].

Para Hildebrand la categoría de importancia adquiere una dimensión fundamental para la ética, y será el concepto que más se asemeje al de valor, pues importancia viene a significar algo que no es indiferente. Algo importante no puede pasar desapercibido. Lo importante es lo que más destaca, lo que mejor se percibe por su mismo carácter de que no es indiferente. Lo importante añade algo puesto que no es indiferente, puesto que resuena. Eso que no es indiferente es el valor. Un objeto neutral que sea indiferente no será entonces objeto de la ética, pues su ser imparcial hace imposible alguna respuesta afectiva. Lo neutral no mueve a la voluntad aunque sí a nuestro conocimiento puesto que también lo neutral tiene su ser propio[14]. Por ello, aunque lo neutral sí tiene un sentido para nuestro conocimiento, no lo tendrá para nuestra voluntad. "Para que un objeto motive nuestra voluntad o cualquier respuesta afectiva, debe estar dotado de algún tipo de importancia, ha de destacarse de la neutralidad o indiferencia"[15]. Partiendo del concepto de importancia Hildebrand definirá el de bien y mal, pues si lo dado tiene una importancia afectiva positiva será bueno, y si tiene una importancia afectiva negativa será malo. Lo asombroso es señalar el matiz que nuestro autor descubre después de definir los conceptos de bueno o malo, a saber, que la oposición entre el bien y el mal no es contradictoria, sino contraria[16]. Es decir, que el mal no es meramente la ausencia del bien, sino un valor con una tonalidad negativa, pues me afecta (no es indiferente, luego es un valor, un disvalor) aunque de un modo negativo. García Morente piensa que el valor es la no-indiferencia pero que se especifica como lo preferible. Para él, el valor es, siempre, no sólo lo no-indiferente, sino además algo positivo y preferible. Pero Hildebrand acepta el mal como valor (disvalor) siempre que se identifique éste con la no-indiferencia. El mal tendría carácter de valor por su importancia negativa.

El concepto de importancia es capital en el pensamiento hildebrandiano, pues se trata de hacer hincapié en que la realidad es la que hace que, en definitiva nosotros nos amoldemos a ella, y no al revés, pues con el carácter de importancia Hildebrand quiere subrayar que lo 
significativo - la importancia- motiva, pero motiva porque es significante, y no al contrario. Es decir, la motivación en sí del sujeto por parte de los hechos no da origen al valor motivador de estos hechos. Este es el inicio, la piedra clave de su realismo fenomenológico con la paradoja de que los motivos son ideales, no reales, pues si fueran reales dejarían de ser motivos para ser causas. Este matiz no es trivial. No distinguir entre motivos y causas es lo que condujo a algunos filósofos a caer en el psicologismo. Los motivos - de motus, mover-mueven a la voluntad, dejando espacio a la libertad. Sin embargo, las causas determinan por su existencia real no dejando margen a la libertad[17].

Para colindar el concepto de bonum, Hildebrand realiza una clasificación de categorías de la importancia, es decir, modos de motivación, formas de destacar la importancia positiva. Estas categorías de la importancia gozan de una evidencia, claridad e inteligibilidad que necesariamente se dan de un modo a priori[18].

La primera categoría de la importancia va a ser la de lo importante en sí mismo. Se trata pues de una importancia intrínseca, vale por sí mismo, pero no como en un mundo ideal, sino como un acto real, como valor objetivo. Por ejemplo el acto del perdón. Dicho acto muestra un valor en sí y nadie puede pasar indiferente, nos marca ver a alguien perdonando una ofensa grave, no puede pasar inadvertido, nos debe llenar de admiración, de lo contrario seríamos semejantes a los animales, hubiéramos perdido tanta sensibilidad que ni siquiera nos conmovemos ante este desprendido acto. Por el contrario existe otra categoría de la importancia, la que vale para el sujeto y no por el objeto en sí. Las cosas buenas nos agradan, y el agrado[19] es la apertura de la importancia, me afecta, de lo contrario sería algo neutral y, por ende, no sería objeto de estudio de la ética. Sería el agrado sólo subjetivamente satisfactorio, inherente al sujeto[20]. Además de lo importante en sí mismo y lo subjetivamente satisfactorio encontramos otra categoría de la importancia, a saber, el bien objetivo para la persona, el bonum mihi[21].

Una vez sabidos los polos objetivos y subjetivos, define la esencia de la moralidad como la respuesta adecuada a eso que nos afecta por su 
carácter de importancia. La ética va a ser así el estudio de las respuestas a los valores que se nos dan.

Entre los dos ejemplos anteriores hay un matiz que resaltar. Lo importante en sí es una categoría intrínseca, mientras que lo importante sólo subjetivamente satisfactorio es extrínseco. Pues bien, el concepto de valor se va a ir definiendo según dicho matiz. Hildebrand lo enuncia así: "Denominamos valor a la importancia intrínseca con que está dotado un acto generoso de perdón, para distinguirla de la importancia de todos aquellos bienes que motivan nuestro interés simplemente porque son agradables o satisfactorios" [22].

Recordando las tres categorías de la importancia que a Hildebrand le vienen dadas mediante una intuición a priori[23], lo importante en sí, lo subjetivamente satisfactorio y el bien objetivo para mí, la primacía de los tres se la lleva el valor en sí, lo importante en sí mismo. Y ¿cómo define Hildebrand el valor? Como "la encarnación de lo que es, en definitiva, objetivamente importante" [24]. Hildebrand ve en el valor algo más que una mera relación. El significado del valor es su importancia, su sentido[25]. El valor no es sólo una categoría sino que además es propiedad del ser, y esta es para Hildebrand la cuestión central. "Los valores pertenecen de tal modo al ser que constituyen precisamente la nota característica de su sentido. Los valores no pueden ser interpretados en ningún caso como meros aspectos relacionales que posee el ser respecto a nuestro deseo y a nuestra voluntad (...) aun cuando los consideremos de un modo puramente contemplativo, continúan resplandeciendo en su intrínseca belleza y plenitud de sentido, en su carácter axiológico y en la obligatoriedad que recubre su ser real" [26].

Dentro de la amplia gama de valores, Hildebrand distingue valores ónticos, valores cualitativos, valores técnicos, y el valor integral de la persona.

Los valores ónticos no tienen opuestos. La persona no tiene un disvalor (Unwert), no existe la no-persona como valor. Sí, por el contrario los valores éticos y estéticos (cualitativos), por ejemplo, la bondad, la justicia, a la que se oponen la maldad, la injusticia. "La diferencia entre lo óntico y lo 
cualitativo es tan clara, que podemos decir que pertenecen a dos géneros distintos de valores"[27]. Pero sobre esto hablaremos más adelante.

Los valores técnicos (también llamados perfectivos) denominan una perfección formal. El valor integral de la persona va más allá que e valor óntico, no depende de la persona sino de la personalidad, y este sobre valor tendrá también un plus en su respuesta, hiper-respuesta (Überwertantwort).

[1] Walter Bruger, Diccionario de filosofía, Herder, octava edición ampliada, Barcelona, 1975, p. 527.

[2] Hildebrand, Dietrich von, Ética, Encuentro, Madrid 1983, p. 154.

[3] Hildebrand, Dietrich von, Moralia, GW IX, Josef Habbel, Regensburg, 1980, p. 449.

[4] Término que usa en los prolegómenos a su Ética, y que también aparece en La esencia del amor.

[5] Hildebrand, Dietrich von, Ética, ob., cit., p. 21.

[6] Alice von Hildebrand, Gran Enciclopedia Rialp, voz "Hildebrand".

[7] Alice von Hildebrand, Alma de León. Biografía de Dietrich von Hildebrand. Prólogo del Card. Raztinger, Palabra, Madrid 2001, p. 27-28.

[8] Hildebrand, Dietrich von, Ética, ob., cit., p. 21-22.

[9] Con lo dado no nos referimos a una producción del sujeto, sino, más bien, al objeto del conocimiento en cuanto presente en la experiencia.

[10] "Éste es el punto esencial: la fenomenología no es un sistema de proposiciones y verdades filosóficas (...) sino un método del filosofar que viene exigido por los problemas que trata la filosofía" A. Von Reinach, Introducción a la fenomenología, Encuentro, Madrid 1986, p. 21. Y también en Hildebrand encontramos el siguiente texto: "Otro peligro que se esconde en una sistematización precipitada es la tendencia a dejarnos llevar por la lógica inmanente del sistema y a preocuparnos más por guardar la consistencia de ese sistema que por hacer justicia a la esencia de un ser", Hildebrand, Dietrich von, Ética, p. 27. 
[11] La contemplación es "dulce respiración de amor (...), una efusión secreta, pacífica y amorosa por la que Dios se nos da" San Juan de la Cruz, Llama de amor viva. Para Hildebrand contemplar significa "(...) demorarse en el presente". Hildebrand, Dietrich von, Nuestra transformación en Cristo, t.1, Rialp, Madrid, 1953, p. 170. Cfr. también en la misma obra, p. 172.

[12] Hildebrand, Dietrich von, Ética, ob., cit., p. 30.

[13] Ibíd., p. 34. También en la p. 200: "Para que algo se haga objeto de nuestra voluntad, debe ser, de uno u otro modo importante".

[14] Habría que aclarar que no hay nada que sea indiferente. Todo ser posee algún valor. "Todo ser posee un cierto valor en la medida en que es algo, en que es un ser". Esto lo explica Hildebrand más adelante, en concreto en la p. 148 y, después, en la p. 151 de su Ética.

[15] Hildebrand, Dietrich von, Ética, ob., cit., p. 34.

[16] "La importancia negativa de un acontecimiento triste no es simplemente la ausencia de un acontecimiento alegre. Se trata de una oposición contraria". Hildebrand, Dietrich von, Ética, ob., cit., p. 36.

[17] Sobre este punto es muy notable la obra de Alexander Pfänder Fenomenología de la voluntad, que incluye la obra Motivo y motivación, traducida por García Morente en Revista de Occidente, Madrid 1931.

[18] Este a priori es claro que se orienta en la esencia, no en la existencia. Ya sabemos que para Hildebrand el conocimiento es recepción de objetos, y para esto es necesaria la experiencia de esencia o lo que llama Hildebrand el a priori. Para dilucidar más la cuestión, Cfr., SánchezMigallón, S., El conocimiento filosófico en Dietrich von Hildebrand, Cuadernos del Anuario Filosófico, Universidad de Navarra, 2002, p. 45-49.

[19] En contra de Meinong, Ortega y Gasset piensa que el valor no agrada porque agrada, sino que "agrada por su gracia o por virtus objetiva". Cfr. Ortega y Gasset, Introducción a una estimativa. ¿Qué son los valores? Encuentro, Madrid, p.21.

[20] Hildebrand pone el ejemplo del elogio al comienzo del capítulo III de su Ética.

[21] "La vida y la libertad no son consideradas aquí únicamente en su valor intrínseco, sino asimismo como grandes dones para mí". Hildebrand, Dietrich von, Ética, ob., cit., p. 57. 
[22] Ibíd., p. 43.

[23] "Algunos objetos, se presentan como un ser-así (Sosein), es decir, una unidad esencialmente necesaria e inteligible y que puede ser captada de manera intuitiva. En tales casos -más frecuentes de los que se piensa-, estamos en presencia del tipo de conocimiento a priori. (...) Hildebrand sostiene que, con este tipo de conocimiento a priori, el hombre es capaz de obtener intuiciones absolutamente ciertas de estados de cosas esencialmente necesarios y altamente inteligibles. Se trata de visiones a priori que trascienden el marco de la relación a nuestra mente y, por tanto, caen fuera de cualquier tipo de idealismo subjetivista, de escepticismo o relativismo, porque se mueven en el mundo de la objetividad y de la validez objetiva" Marcos Martín, J. J., Afectividad y vida moral cristiana según Dietrich von Hildebrand, Edusc, Roma, 2007, p. 129.

[24] Hildebrand, Dietrich von, Ética, ob., cit., p. 55.

[25] En este sentido, es muy afín al pensamiento de Hildebrand la definición que da Juan Pablo II del valor como "(...) las luces que iluminan la existencia y, a medida que el hombre se trabaja a sí mismo, brillan cada vez más intensamente en el horizonte de su vida". Juan Pablo II, Memoria e identidad, Madrid 2005, p. 43.

[26] Ibíd., p. 93.

[27] Hildebrand, Dietrich von, Ethik, p. 145. 